\title{
FFQ for the adult population of the capital of Ecuador (FFQ-Quito): development, reliability and validity
}

\author{
Katherine M Silva-Jaramillo ${ }^{1,2, *}$, Marilda B Neutzling ${ }^{1,3}$ and Michele Drehmer ${ }^{1,3}$ \\ 'Department of Social Medicine, School of Medicine, Postgraduate Studies Program in Epidemiology, Federal \\ University of Rio Grande do Sul, Rua Ramiro Barcelos 2400, 90035-003 Porto Alegre, Brazil: ${ }^{2}$ Ministerio de Salud \\ Pública del Ecuador (Ministry of Public Health of Ecuador), Quito, Ecuador: ${ }^{3}$ Department of Nutrition, School of \\ Medicine, Federal University of Rio Grande do Sul, Porto Alegre, Brazil
}

Submitted 21 August 2014: Final revision received 27 November 2014: Accepted 22 December 2014: First published online 29 January 2015

\begin{abstract}
Objective: To assess the reliability and validity of a semi-quantitative FFQ designed to evaluate the usual nutrient intake of adults in Quito, Ecuador.

Design: Dietary data using $24 \mathrm{~h}$ recalls (24hR) were used to design a list of commonly consumed foods. The relative validity of a 111-item FFQ was evaluated by comparing nutrient intakes against three non-consecutive $24 \mathrm{hR}$. All nutrients were energy-adjusted. Reliability was assessed using two FFQ (FFQ1 and FFQ2) and assessed by the intra-class correlation coefficient. The comparisons between the FFQ and the $24 \mathrm{hR}$ were assessed by the de-attenuated Pearson correlation coefficient, weighted kappa and by Bland-Altman plots.

Setting: Quito, Ecuador.

Subjects: Overall, 345 adults were enrolled in the present study. Two hundred and fifty participated in FFQ development and ninety-five participated in the FFQ validity and reliability.

Results: The FFQ produced higher energy and nutrient intakes. Reliability correlation coefficients after adjusting for energy ranged from 0.62 to 0.88 for protein and $\mathrm{Ca}$, respectively. For the validity study, energy-adjusted and de-attenuated correlation coefficients between the questionnaire and the $24 \mathrm{hR}$ ranged from $0 \cdot 21$ for fat to 0.65 for Ca. Only $4 \%$ of the participants were grossly misclassified and $46 \%$ had weighted kappa higher than 0.42 . The Bland-Altman plot showed a constant bias with a tendency to increase according to the intake level.

Conclusions: The FFQ showed reasonably good relative validity and reliable measurements, especially for nutrients considered protective and risk markers of non-communicable disease, and can be used to assess usual nutrient intake in this population.
\end{abstract}

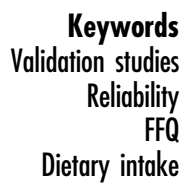

Chronic non-communicable diseases are the global health problem of greatest magnitude and represent $58 \%$ of all causes of death. The total burden of these diseases falls mainly on low- and middle-income countries ${ }^{(1,2)}$. In 2008, about $65 \%$ of deaths in Ecuador were attributable to chronic non-communicable diseases (including diabetes, cancer, cardiovascular and respiratory diseases) ${ }^{(1)}$. According to the Ecuadorian National Health and Nutrition Survey carried out in 2012, metabolic syndrome was present in more than $35 \%$ of the adult population aged 20 to 59 years $^{(3)}$. Evidence shows that at least $40 \%$ of all deaths in individuals affected by these chronic conditions each year are attributed to the consumption of foods with high contents of saturated and trans fats, $\mathrm{Na}$ and sugar ${ }^{(4)}$.

Previous epidemiological studies have shown consistent associations between usual dietary intake and the occurrence of these diseases ${ }^{(5,6)}$. Several methods such as food records, multiple $24 \mathrm{~h}$ recalls and FFQ are used to measure dietary intake. Food records and multiple $24 \mathrm{~h}$ recalls are accurate methods for assessing food intake but the cost, time, motivation and literacy of participants are important factors that can limit the use of these instruments in large epidemiological studies. Therefore, the FFQ has been the most widely used method because of its practicality, low cost and ability to report usual intake, defined as the long run average of daily intakes of a dietary component by an individual ${ }^{(7)}$, which is the main interest in studies on the effects of diet on long-term health ${ }^{(8-12)}$.

As with all dietary assessment methods, the FFQ also has some limitations. An FFQ developed for a given population cannot be readily used in other populations 
because demographic, socioeconomic, cultural and other differences influence the food intake of each population, so that incorrect estimates of exposure can lead to false associations $^{(9,10,13)}$. Consequently, accuracy and precision in food intake estimates need to be evaluated by studying the validity and reliability of the FFQ in each population. There is no gold standard to develop or validate an FFQ, but multiple $24 \mathrm{~h}$ recalls are used as a reference method by $75 \%$ of validation studies ${ }^{(13)}$.

Although several validated questionnaires that have been adapted for cultural variations are currently in use in Latin America $^{(12,14-18)}$, to our knowledge, no FFQ had previously been developed and validated for the Ecuadorian population. Therefore, the goal of the present study was to assess the reliability and validity of an FFQ designed to evaluate the usual nutrient intake of the adult population of the Metropolitan District of Quito, Ecuador, during the past year.

\section{Methods}

The study was conducted in Quito, Ecuador between November 2011 and August 2012 and comprised two phases: (i) the development of a semi-quantitative FFQ; and (ii) assessment of the reliability and validity of the FFQ. Initially, the FFQ food list was compiled from information based on $24 \mathrm{~h}$ dietary recalls (24hR). For the reliability and validity study, we administered three $24 \mathrm{hR}$, which is considered to be the standard method, and two FFQ. The study design is shown in Fig. 1.

\section{FFQ development}

The FFQ was developed based on $24 \mathrm{hR}$ administered to a convenience sample of 250 adults of both sexes of high, medium or low socio-economic status and living in Quito. Of the 250 participants, 134 (53.6\%) were males and $116(46.4 \%)$ were females, with a mean age of 36.6 (SD 14.3) years. The interviews were performed in different locations in the city of Quito (parks, shopping centres, mass gathering places, markets, etc.). The locations were

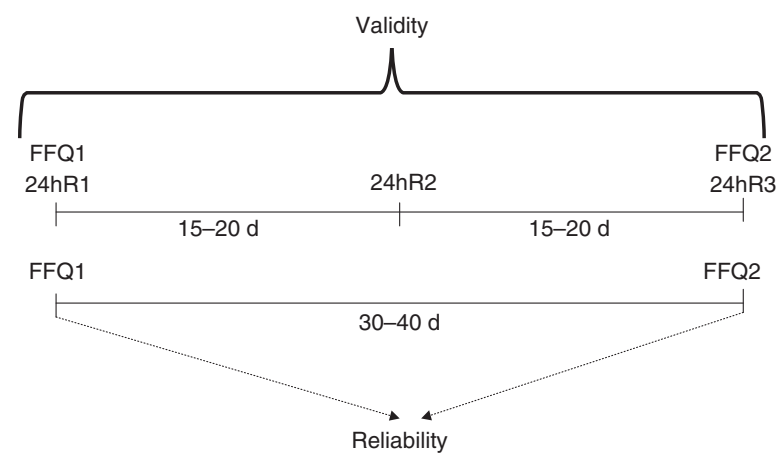

Fig. 1 Design of the FFQ-Quito validity and reliability study (FFQ1 and FFQ2, first and second administration of the FFQ, respectively; 24hR1, 24hR2 and $24 \mathrm{hR} 3$, first, second and third $24 \mathrm{~h}$ recall, respectively) considered proxies for socio-economic level. In order to administer the $24 \mathrm{hR}$, we developed a specific protocol with an instruction manual and conducted intensive interviewer training on the detailed collection of dietary intake data using a photographic album of food servings and eating utensils ${ }^{(19,20)}$. The $24 \mathrm{hR}$ were administered from Monday to Saturday. The FFQ list included all food items that had appeared with a frequency of $5 \%$ or more in the $24 \mathrm{hR}$ and those with the highest percentage of relative contribution for the following nutrients: carbohydrate, protein, total fat, vitamin $\mathrm{C}$, vitamin $\mathrm{A}, \mathrm{Ca}, \mathrm{Fe}, \mathrm{K}$ and $\mathrm{Na}$. The relative contribution of each nutrient (e.g. vitamin A) consumed by the population was estimated by the weighted sum of that nutrient in all servings of all foods reported ${ }^{(21)}$. The proportional contribution provided by a particular food $i$ is determined by:

$\frac{\text { Total nutrient (e.g. vitamin A) provided by food } i}{\text { Total nutrient (e.g. vitamin A) provided by all foods }} \times 100$.

Thus, we selected food items that were responsible for approximately $90 \%$ of the total intake of energy and each selected nutrient.

In addition to the foods recorded in the original $24 \mathrm{hR}$, three traditional items that are commonly consumed in Quito were added (hominy, corn and fried pork), as well as two processed foods that are an increasingly prominent part of the diet (pizza and hamburger), and beef liver because it is rich in $\mathrm{Fe}$, protein and vitamin $\mathrm{A}$. In all, 110 food items were included. In order to determine the usual serving of each food item, we used the average of servings (in grams) reported in the $24 \mathrm{hR}$. After conducting a pilot study ( $n 35$ ), we noted that it was necessary to add five other foods (beets, string beans, oat soup, coffee and broad beans) and remove four (mango, cabbage, Swiss chard and giblets). Accordingly, the final version of the FFQ included 111 food items divided into eleven groups: (i) dairy foods; (ii) fruit; (iii) greens and vegetables; (iv) rice and tubers including potatoes; (v) legumes and eggs; (vi) meat and seafood; (vii) soups; (viii) cereals and flours; (ix) drinks; (x) sweets and desserts; and (xi) miscellaneous or others. Frequency of consumption was based on the FFQ published by Sichieri and Everhart, with eight response options ranging from 'never or almost never' to 'more than three times/day' (22). The final version of the FFQ-Quito is presented in the online supplementary material.

\section{Reliability and validity study}

Sample

One hundred and twenty adults between 20 and 65 years of age who were employees of a university in Quito were selected and recruited for participation in the reliability and validity study. The sample size calculation was based on the guidelines of Burley et al., which recommend a sample of fifty to 100 people for this type of study ${ }^{(23)}$. 
Sampling was random and took into account the size ratio of each job category (support staff, technical staff and faculty) as a proxy for socio-economic status. Individuals under medical or nutritional treatment during the previous month and pregnant women were excluded from the study.

\section{FFQ reliability}

The reliability of the tool was determined using the testretest methodology. The study participants responded to the FFQ at baseline (FFQ1) and at the end of the study (FFQ2), with an average interval of 30 to $40 \mathrm{~d}$. For the purpose of reliability, the same interviewer conducted both interviews.

\section{FFQ validity}

The average consumption of foods and nutrients reported in three non-consecutive $24 \mathrm{hR}$ was used as a reference dietary intake. The dietary surveys were administered by trained interviewers from the university nutrition course, starting with the FFQ and then the $24 \mathrm{hR}^{(13)}$. To ensure the quality of the data, we developed an explanatory manual with specific protocols for standardizing the interviews and ensuring the correct completion of the FFQ and the $24 \mathrm{hR}$. In the introduction of the FFQ and for each food group, the interviewer repeated that answers should be based on the previous 12 months. Next, the list of food items was read aloud and respondents were asked how many times the consumption of each item occurred per day, week or month and how many servings were consumed each time.

The $24 \mathrm{R}$ were collected over a period of 4 months with an interval of 15 to $20 \mathrm{~d}$ between each interview. We used a standard form for administering the $24 \mathrm{hR}$ and followed the multiple-pass approach for its completion ${ }^{(24)}$. In each interview, the participant was encouraged to thoroughly report all foods and beverages consumed in the last $24 \mathrm{~h}$, as well as their respective amounts, sizes, number of servings and preparation methods. A photographic food atlas was used to reduce inaccuracies in reporting the size or volume of food consumed ${ }^{(19,20)}$. In order to include the weekend food consumption, which in many parts of the world is likely to be different from that during the working week, one of the interviews was conducted on a Monday.

\section{Estimates of nutritional composition}

In order to estimate the nutritional composition of the food items included in the FFQ and of those food items reported in the $24 \mathrm{hR}$, we used the Ecuadorian National Health and Nutrition Survey food composition table ${ }^{(25)}$, the US Department of Agriculture food composition and nutrient database release $25^{(26)}$ and information from commercial food labels. The ADSnutri software ${ }^{(27)}$ was used to quantify the nutritional content from the $24 \mathrm{hR}$. In order to determine the nutrients from the FFQ, a syntax was developed in the PASW statistical software package version 18, based on the following calculation: quantity of servings consumed per time $\times$ weight (in grams) $\times$ frequency of consumption $\times$ nutritional composition of the food serving. The coefficients used for the daily frequency equivalents were the following: 3 for $>3$ times/d; 2 for 2-3 times/d; 1 for 1 time/d; 0.79 for 5-6 times/week; 0.43 for 2-4 times/week; 0.14 for 1 time/week; 0.07 for 1-3 times/ month; and 0 for never/almost never.

\section{Statistical analyses}

For all nutrients examined, normality was verified and the means and standard deviations were estimated. For those nutrients not showing a normal distribution, logarithmic transformation was performed; in particular, this procedure was necessary for $\mathrm{Ca}$ and cholesterol in the reliability analyses. The differences and ratios between the mean values obtained with the FFQ and the $24 \mathrm{hR}$ were calculated. Paired $t$ tests were used to determine statistically significant differences between means. Additionally, beanplots of centesimal values of energy and nutrients from the FFQ and $24 \mathrm{hR}$ were built. This procedure combines a one-dimensional scatter plot with an estimated density curve ${ }^{(28)}$.

For reliability analyses, we used the intra-class correlation coefficient (ICC) per point and $95 \% \mathrm{CI}$; the model that was used specifies the random effect for individuals. The validity of the FFQ was assessed by comparing the nutrient intake estimates using the average of the two FFQ and the average for the three days of the $24 \mathrm{hR}$ using the Pearson correlation coefficient $(r)$. In order to correct the estimates of nutrients for total energy intake, an adjustment by energy was made using the method proposed by Willett et al.: the correction by energy was made by computing the residuals of the regression model, with energy intake as an independent variable and nutrient intake as a dependent variable ${ }^{(29)}$. Due to the occurrence of within-subject variability in food intake, the correlation coefficients were corrected by the ratio of the within- to between-subject variances in the three $24 \mathrm{hR}$ using the following formula:

$$
r_{\mathrm{v}}=r_{\mathrm{O}}\left(1+\frac{\lambda}{n}\right)^{1 / 2}
$$

where $r_{\mathrm{V}}$ is the true correlation, $r_{\mathrm{O}}$ is the observed correlation between the average of the FFQ and the average of the $24 \mathrm{hR}, \lambda$ is the ratio of within- to between-subject variances in the $24 \mathrm{hR}$ and $n$ is the number of replicates; in this case, three recalls ${ }^{(30,31)}$. The components of the variance within and between subjects were established by conducting ANOVA.

The agreement between each FFQ and the average of the three $24 \mathrm{hR}$ was also evaluated by classifying participants according to their distributions into quartiles of energy and other nutrient intakes for each method. 
The percentages of exact agreement (classification in the same quartile) and disagreement (classification in opposite quartiles) were estimated. For this analysis, the classification into quartiles was compared by using the weighted kappa statistic $\left(\kappa_{\mathrm{w}}\right)$.

In order to evaluate the level of discrepancy between energy and nutrient values calculated by both methods (FFQ and 24hR), we built scatter plots with the mean intake values obtained by the two methods on the $x$-axis and the absolute differences in intake (bias) between the two methods on the $y$-axis according to the Bland-Altman $\operatorname{method}^{(32,33)}$. For the scatter plots, we calculated the $95 \%$ limits of agreement (LOA), which were obtained as: $\bar{d} \pm 1.96 \times S D$, where $\bar{d}$ is the bias and $S D$ is the standard deviation. These analyses were performed using the $\mathrm{R}$ statistical program version $2 \cdot 15 \cdot 2$ and the PASW statistical software package version 18.

\section{Ethical considerations}

This research project was approved by the Ethics Committees at the Universidad San Francisco de Quito (Ecuador) and at the Universidade Federal do Rio Grande do Sul (Brazil). Survey participants were informed about the purposes of the study and gave their consent by signing the informed consent form.

\section{Results}

Of the 120 individuals selected, twelve (10.0\%) refused to participate in the study and ten ( $8.3 \%)$ did not meet the inclusion criteria. Among the individuals who refused to participate in the study, $60 \%$ were male, with a mean age of 42 years, and occupied positions as support staff, technical staff and faculty members. Among the participants ( $n$ 98), $97 \%$ completed the validation and reliability study. Thus, the final sample comprised ninety-five adults, with a mean age of 40 (SD 11.2) years, of whom $64.2 \%$ were females. According to job categories, faculty members represented forty-seven participants (twenty males and twenty-seven females) with a mean age of 39 (SD 12.0) years, technical staff comprised thirty-two participants (seven males and twenty-five females) with a mean age 38.8 (SD 11.2) years and sixteen participants were support staff (seven males and nine females) with a mean age $46 \cdot 3$ (SD 10.5) years.

Table 1 shows the mean values and standard deviations for energy and nutrients obtained from FFQ1 and FFQ2. The average intakes of energy and all nutrients analysed were lower in FFQ2 compared with FFQ1. Table 1 also shows the crude and adjusted ICC values for energy and nutrients measured by the FFQ on both occasions. ICC values adjusted for energy ranged from 0.62 (protein) to $0 \cdot 88(\mathrm{Ca})$.

Figure 2 reveals that there were differences between the daily energy and nutrient distribution profiles obtained by the average of both FFQ and the average of the three 24hR. Based on the FFQ, the energy distribution showed a higher mean, greater amplitude, more extreme minimum and maximum consumption values, as well as a concentration of intake between $6276 \mathrm{~kJ}$ and $18828 \mathrm{~kJ}$ (1500 $\mathrm{kcal}$ and $4500 \mathrm{kcal})$. On the other hand, energy dispersion was smaller in the $24 \mathrm{hR}$, with a concentration of intake of between $5439 \mathrm{~kJ}$ and $12552 \mathrm{~kJ}$ (1300 kcal and $3000 \mathrm{kcal})$. The same tendency was observed in all nutrients studied, in that there was a higher mean and a greater amplitude of the density and dispersion curve for the FFQ data compared with the $24 \mathrm{hR}$ data.

Table 1 Mean daily energy and nutrient intake estimates from the first (FFQ1) and second (FFQ2) administration of the FFQ-Quito, and intra-class correlation coefficients (ICC) between the two administrations (FFQ1 v. FFQ2); ninety-five adults, Quito, Ecuador, November 2011-August 2012

\begin{tabular}{|c|c|c|c|c|c|c|c|c|}
\hline \multirow[b]{3}{*}{ Nutrient } & \multirow{2}{*}{\multicolumn{2}{|c|}{ FFQ1 }} & \multirow{2}{*}{\multicolumn{2}{|c|}{ FFQ2 }} & \multicolumn{4}{|c|}{ ICC between FFQ1 and FFQ2 } \\
\hline & & & & & \multicolumn{2}{|c|}{ Unadjusted } & \multicolumn{2}{|c|}{ Energy-adjusted } \\
\hline & Mean & SD & Mean & SD & ICC & $95 \% \mathrm{Cl}$ & ICC & $95 \% \mathrm{Cl}$ \\
\hline Energy (kJ) & $10467 \cdot 20$ & $3514 \cdot 18$ & 10039.05 & 3446.49 & 0.87 & $0.80,0.91$ & - & - \\
\hline Energy (kcal) & $2501 \cdot 72$ & 839.91 & $2399 \cdot 39$ & 823.73 & 0.87 & $0.80,0.91$ & - & - \\
\hline Total fat $(\mathrm{g})$ & 75.90 & 30.02 & $71 \cdot 11$ & 27.81 & 0.84 & $0.76,0.90$ & 0.76 & $0.64,0.84$ \\
\hline Fibre $(\mathrm{g})$ & 23.64 & 8.21 & $23 \cdot 30$ & 9.08 & 0.83 & $0.74,0.88$ & 0.81 & $0.72,0.88$ \\
\hline Carbohydrate (g) & 350.57 & $122 \cdot 89$ & $342 \cdot 11$ & $123 \cdot 20$ & 0.85 & $0.78,0.90$ & 0.77 & $0.65,0.85$ \\
\hline Protein $(\mathrm{g})$ & 104.79 & 38.40 & 98.55 & 36.49 & 0.86 & $0.79,0.91$ & 0.62 & $0.44,0.75$ \\
\hline 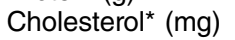 & $312 \cdot 70$ & 151.97 & $285 \cdot 81$ & 135.57 & 0.85 & $0.77,0.90$ & 0.71 & $0.57,0.81$ \\
\hline Saturated fat (g) & 22.97 & 22.97 & 21.43 & 9.06 & 0.81 & $0.72,0.88$ & 0.81 & $0.72,0.85$ \\
\hline $\mathrm{Ca}^{*}(\mathrm{mg})$ & $1055 \cdot 75$ & 451.87 & $1008 \cdot 48$ & 474.01 & 0.88 & $0.82,0.92$ & 0.88 & $0.82,0.92$ \\
\hline $\mathrm{Fe}(\mathrm{mg})$ & $16 \cdot 76$ & $6 \cdot 10$ & $16 \cdot 35$ & 5.58 & $0 \cdot 81$ & $0.72,0.88$ & 0.74 & $0.61,0.83$ \\
\hline $\mathrm{K}(\mathrm{mg})$ & 3359.56 & $1120 \cdot 16$ & 3211.00 & $1166 \cdot 25$ & 0.84 & $0.76,0.90$ & 0.79 & $0.69,0.86$ \\
\hline $\mathrm{Na}(\mathrm{mg})$ & 1858.46 & $800 \cdot 31$ & $1767 \cdot 25$ & 809.45 & 0.84 & $0.76,0.90$ & 0.87 & $0.80,0.91$ \\
\hline Vitamin A† $(\mu \mathrm{g})$ & $1056 \cdot 81$ & $450 \cdot 76$ & 992.53 & 456.07 & 0.77 & $0.66,0.85$ & 0.68 & $0.52,0.79$ \\
\hline Vitamin C (mg) & $266 \cdot 21$ & $120 \cdot 72$ & $256 \cdot 60$ & 128.07 & 0.80 & $0.70,0.87$ & 0.81 & $0.72,0.88$ \\
\hline
\end{tabular}

*Log-transformed nutrients.

†Retinol equivalents. 
(a)

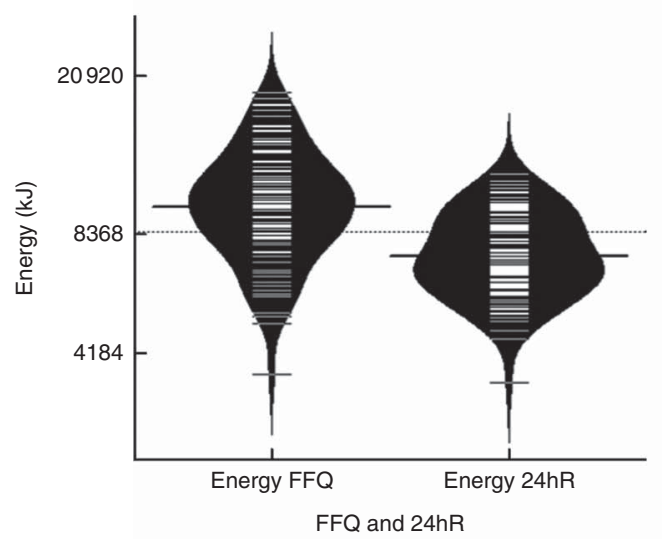

(c)

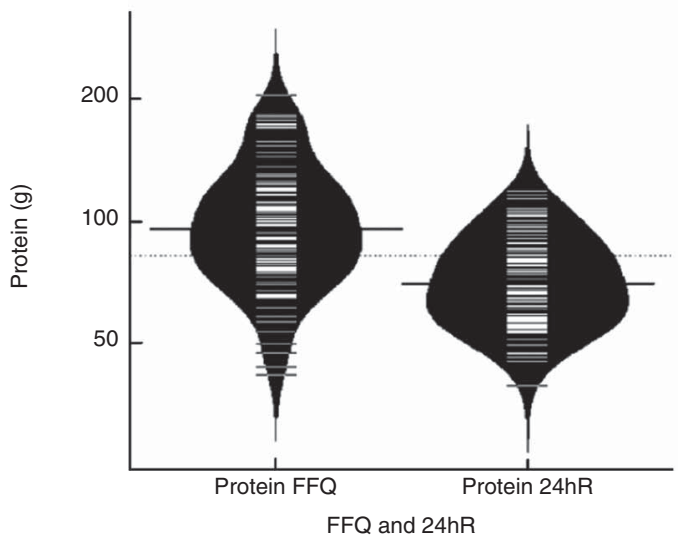

(b)

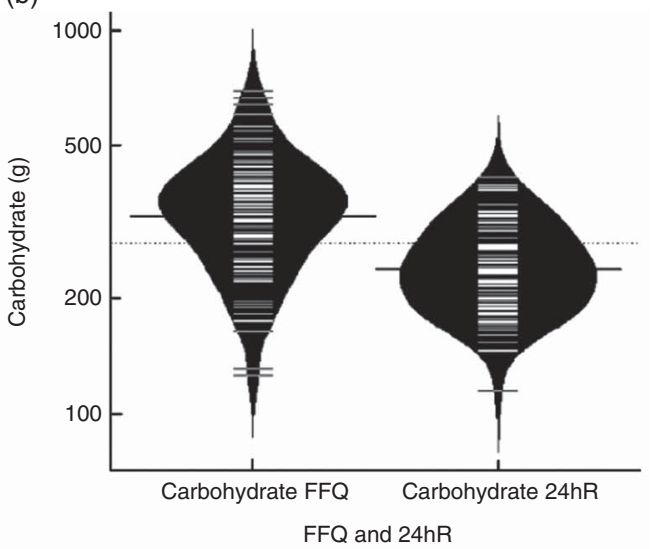

(d)

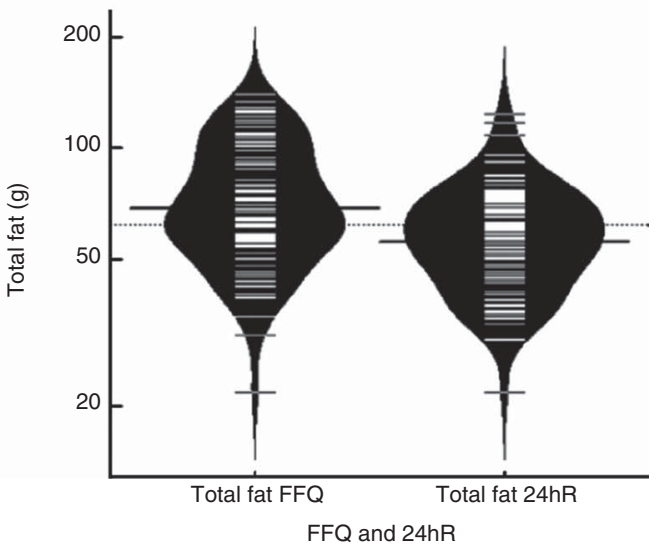

Fig. 2 Beanplots of estimated intakes of (a) energy, (b) carbohydrate, (c) protein and (d) total fat, as measured by the average of two FFQ and three $24 \mathrm{~h}$ recalls (24hR), among ninety-five adults, Quito, Ecuador, November 2011-August 2012. Dotted line represents the average of observation considering both methods (FFQ and 24hR). Solid black line within the shapes represents the average of observations for each method. Grey lines within the shapes (thinner lines) represent the value of each observation

Table 2 Mean daily energy and nutrient intake estimates from the average of the first (FFQ1) and second (FFQ2) administration of the FFQQuito and the average of the three $24 \mathrm{~h}$ recalls $(24 \mathrm{hR} 1,24 \mathrm{hR} 2$ and $24 \mathrm{hR} 3)$, differences between the two dietary methods, $24 \mathrm{hR}$ variance ratio, and Pearson correlation coefficients ( $r$ ) between the two dietary methods (FFQ v. 24hR); ninety-five adults, Quito, Ecuador, November 2011-August 2012

\begin{tabular}{|c|c|c|c|c|c|c|c|c|c|c|c|}
\hline \multirow[b]{3}{*}{ Nutrient } & \multirow{2}{*}{\multicolumn{2}{|c|}{$\begin{array}{c}\mathrm{FFQ} \\
{[(\mathrm{FFQ} 1+\mathrm{FFQ} 2) / 2]} \\
\end{array}$}} & \multirow{2}{*}{\multicolumn{2}{|c|}{$\begin{array}{c}24 h R \\
{[(24 h R 1+24 h R 2+} \\
24 h R 3) / 3] \\
\end{array}$}} & \multirow{2}{*}{\multicolumn{2}{|c|}{$\begin{array}{c}\text { Difference } \\
(\mathrm{FFQ}-24 \mathrm{hR})\end{array}$}} & \multirow{3}{*}{$\begin{array}{l}\text { Variance } \\
\text { ratio } 24 \mathrm{hR}^{\star}\end{array}$} & \multicolumn{4}{|c|}{ Pearson $r$} \\
\hline & & & & & & & & \multicolumn{2}{|c|}{ Unadjusted } & \multicolumn{2}{|c|}{ Energy-adjusted } \\
\hline & Mean & SD & Mean & SD & Mean & SD & & Crude & De-attenuated & Crude & De-attenuated \\
\hline Energy (kJ) & $10253 \cdot 14$ & $3267 \cdot 70$ & $7557 \cdot 02$ & $1816 \cdot 65$ & $2696 \cdot 12 \ddagger$ & 2794.54 & - & - & - & - & - \\
\hline Energy (kcal) & $2450 \cdot 56$ & $781 \cdot 18$ & $1806 \cdot 17$ & $434 \cdot 19$ & $644.39 \ddagger$ & $667 \cdot 91$ & - & 0.52 & 0.55 & - & - \\
\hline Total fat $(\mathrm{g})$ & 73.51 & 26.96 & 58.64 & 18.98 & $29 \cdot 17 \ddagger$ & $30 \cdot 48$ & 0.42 & 0.37 & 0.39 & 0.20 & 0.21 \\
\hline Fibre (g) & $23 \cdot 47$ & 7.99 & $16 \cdot 87$ & 7.05 & $6.59 \ddagger$ & $8 \cdot 19$ & 0.40 & 0.44 & 0.47 & 0.50 & 0.53 \\
\hline Carbohydrate (g) & $346 \cdot 34$ & 114.72 & $245 \cdot 45$ & $64 \cdot 20$ & $100 \cdot 88 \ddagger$ & $99 \cdot 49$ & 0.43 & 0.50 & 0.53 & 0.39 & 0.42 \\
\hline Protein (g) & $101 \cdot 67$ & $35 \cdot 21$ & 72.49 & $18 \cdot 34$ & $29 \cdot 17 \ddagger$ & $3 \cdot 12$ & 0.48 & 0.50 & 0.54 & 0.33 & 0.36 \\
\hline Cholesterol (mg) & $299 \cdot 26$ & 134.49 & $207 \cdot 52$ & $108 \cdot 45$ & $26.55 \ddagger$ & 2.72 & 0.46 & 0.48 & 0.52 & 0.42 & 0.45 \\
\hline Saturated fat $(\mathrm{g})$ & $22 \cdot 20$ & 8.82 & $17 \cdot 80$ & $6 \cdot 68$ & $4.40 \ddagger$ & $9 \cdot 17$ & 0.54 & 0.32 & 0.35 & 0.44 & 0.48 \\
\hline $\mathrm{Ca}(\mathrm{mg})$ & $1032 \cdot 11$ & $1032 \cdot 12$ & $437 \cdot 63$ & $291 \cdot 84$ & $349 \cdot 61 \ddagger$ & $35 \cdot 86$ & 0.38 & 0.57 & 0.61 & 0.61 & 0.65 \\
\hline $\mathrm{Fe}(\mathrm{mg})$ & $35 \cdot 33$ & $16 \cdot 56$ & 10.99 & 3.49 & $5.56 \ddagger$ & 55.59 & 0.68 & 0.26 & 0.29 & 0.30 & 0.33 \\
\hline $\mathrm{K}(\mathrm{mg})$ & $3285 \cdot 28$ & 1064.47 & 2083.83 & 679.49 & $1201.45 \ddagger$ & 938.84 & 0.39 & 0.49 & 0.52 & 0.58 & 0.62 \\
\hline $\mathrm{Na}(\mathrm{mg})$ & $1812 \cdot 86$ & $748 \cdot 31$ & $1651 \cdot 43$ & $641 \cdot 15$ & $161.42 \ddagger$ & $710 \cdot 65$ & 0.60 & 0.49 & 0.54 & 0.48 & 0.53 \\
\hline Vitamin A† $(\mu \mathrm{g})$ & $1024 \cdot 67$ & $410 \cdot 04$ & $496 \cdot 70$ & $299 \cdot 85$ & $597 \cdot 27 \ddagger$ & $421 \cdot 74$ & 0.81 & 0.30 & 0.34 & 0.35 & 0.39 \\
\hline Vitamin C (mg) & 261.40 & 113.59 & $156 \cdot 14$ & 91.08 & $105 \cdot 26 \ddagger$ & 101.92 & 0.38 & 0.52 & 0.55 & 0.58 & 0.62 \\
\hline
\end{tabular}

${ }^{*}$ Between-subjects/within-subject.

†Retinol equivalents.

$\ddagger$ Mean values were significantly different from those estimated from $24 \mathrm{hR}: P<0.05$ (paired $t$-test). 
Table 3 Percentages of participants classified into the same and opposite intake quartiles according to the average of the first and second administration of the FFQ-Quito and the average of the three $24 \mathrm{~h}$ recalls, and weighted kappa statistics $\left(\kappa_{\mathrm{w}}\right)$; ninety-five adults, Quito, Ecuador, November 2011-August 2012

\begin{tabular}{|c|c|c|c|c|c|c|c|c|}
\hline \multirow[b]{2}{*}{ Nutrient } & \multicolumn{4}{|c|}{ Unadjusted } & \multicolumn{4}{|c|}{ Energy-adjusted } \\
\hline & $\begin{array}{l}\text { Agreement in } \\
\text { same quartile }\end{array}$ & $\begin{array}{l}\text { Misclassification in } \\
\text { opposite quartile }\end{array}$ & $\kappa_{\mathrm{w}}$ & $95 \% \mathrm{Cl}$ & $\begin{array}{l}\text { Agreement in } \\
\text { same quartile }\end{array}$ & $\begin{array}{l}\text { Misclassification in } \\
\text { opposite quartile }\end{array}$ & $\kappa_{\mathrm{w}}$ & $95 \% \mathrm{Cl}$ \\
\hline Energy $(\mathrm{kJ})$ & 31.6 & $2 \cdot 2$ & 0.39 & $0.22,0.55$ & - & - & - & - \\
\hline Total fat (g) & $25 \cdot 3$ & 4.3 & 0.27 & $0.11,0.44$ & $27 \cdot 4$ & $7 \cdot 4$ & 0.25 & $0.08,0.44$ \\
\hline Fibre $(\mathrm{g})$ & $39 \cdot 0$ & 3.3 & 0.45 & $0.24,0.58$ & $41 \cdot 1$ & $1 \cdot 1$ & 0.50 & $0.35,0.63$ \\
\hline Carbohydrate (g) & 43.2 & $3 \cdot 3$ & 0.44 & $0.26,0.58$ & $31 \cdot 6$ & $5 \cdot 3$ & 0.34 & $0.16,0.51$ \\
\hline Protein $(\mathrm{g})$ & $34 \cdot 8$ & $2 \cdot 2$ & 0.44 & $0.27,0.60$ & $34 \cdot 8$ & $5 \cdot 3$ & 0.31 & $0.12,0.49$ \\
\hline Cholesterol (mg) & $44 \cdot 2$ & 4.3 & 0.45 & $0.27,0.62$ & $43 \cdot 1$ & $5 \cdot 3$ & 0.42 & $0.23,0.59$ \\
\hline Saturated fat (g) & $31 \cdot 6$ & 7.4 & 0.24 & $0.04,0.43$ & 49.5 & $6 \cdot 3$ & 0.41 & $0.21,0.59$ \\
\hline $\mathrm{Ca}(\mathrm{mg})$ & $41 \cdot 1$ & 3.3 & 0.46 & $0.28,0.60$ & $52 \cdot 7$ & 0.0 & 0.62 & $0.47,0.72$ \\
\hline $\mathrm{Fe}(\mathrm{mg})$ & 29.5 & 8.5 & 0.20 & $0.02,0.42$ & $37 \cdot 8$ & $6 \cdot 3$ & 0.30 & $0.07,0.48$ \\
\hline $\mathrm{K}(\mathrm{mg})$ & $46 \cdot 3$ & $2 \cdot 1$ & 0.58 & $0.41,0.71$ & $40 \cdot 0$ & $2 \cdot 1$ & 0.52 & $0.35,0.66$ \\
\hline $\mathrm{Na}(\mathrm{mg})$ & 38.9 & $4 \cdot 3$ & 0.41 & $0.23,0.58$ & 48.4 & $2 \cdot 1$ & 0.56 & $0.38,0.69$ \\
\hline Vitamin $A^{*}(\mu \mathrm{g})$ & $40 \cdot 0$ & $6 \cdot 4$ & 0.39 & $0.20,0.56$ & $35 \cdot 7$ & $6 \cdot 3$ & 0.29 & $0.09,0.46$ \\
\hline Vitamin C (mg) & 43.2 & 4.3 & 0.51 & $0.34,0.66$ & $45 \cdot 3$ & $2 \cdot 2$ & 0.53 & $0.36,0.69$ \\
\hline
\end{tabular}

*Retinol equivalents.

Table 4 Mean daily energy and nutrient intake differences and limits of agreement between the average of the first and second administration of the FFQ-Quito and the average of the three $24 \mathrm{~h}$ recalls; ninety-five adults, Quito, Ecuador, November 2011-August 2012

\begin{tabular}{|c|c|c|c|}
\hline Nutrient & Mean difference (FFQ - 24hR) & Upper limit of agreement & Lower limit of agreement \\
\hline Energy (kJ) & $2696 \cdot 13 \dagger$ & 8173.40 & $2781 \cdot 15$ \\
\hline Energy (kcal) & $644 \cdot 39 \dagger$ & 1953.49 & $-664 \cdot 71$ \\
\hline Total fat $(\mathrm{g})$ & $29.17 \dagger$ & 88.91 & -30.57 \\
\hline Fibre (g) & $6.59 \dagger$ & $22 \cdot 64$ & -9.46 \\
\hline Carbohydrate (g) & $100 \cdot 88 \dagger$ & 295.88 & $-94 \cdot 12$ \\
\hline Protein $(\mathrm{g})$ & $29.17 \dagger$ & 35.29 & 23.05 \\
\hline Cholesterol (mg) & $26.55 \dagger$ & 31.88 & $21 \cdot 22$ \\
\hline Saturated fat $(\mathrm{g})$ & $4.40 \dagger$ & $22 \cdot 37$ & -13.57 \\
\hline $\mathrm{Ca}(\mathrm{mg})$ & $349.61 \dagger$ & $419 \cdot 90$ & 279.32 \\
\hline $\mathrm{Fe}(\mathrm{mg})$ & $5.56 \dagger$ & 114.52 & -103.40 \\
\hline $\mathrm{K}(\mathrm{mg})$ & $1201.45 \dagger$ & 3041.58 & -638.68 \\
\hline $\mathrm{Na}(\mathrm{mg})$ & $161.42 \dagger$ & 1554.29 & -1231.45 \\
\hline Vitamin $A^{*}(\mu \mathrm{g})$ & $597 \cdot 27 \dagger$ & 1423.88 & $-229 \cdot 34$ \\
\hline Vitamin C (mg) & $105 \cdot 26 \dagger$ & 305.02 & -94.50 \\
\hline
\end{tabular}

${ }^{\star}$ Retinol equivalents.

†All mean differences (biases) between the methods were significant: $P<0.05$ (paired $t$ test).

Table 2 shows the values for mean intake of energy and each nutrient estimated by the average of both FFQ and the three $24 \mathrm{hR}$, as well as the variance ratios of the $24 \mathrm{hR}$. Intakes of energy and other nutrients measured by the FFQ were higher than intakes measured by the reference method (24hR). Also, the within-subject variance was greater than the between-subject variance for most nutrients. Table 2 also shows the crude, adjusted and de-attenuated Pearson correlation coefficients $(r)$ for within-subject variance between the two dietary methods (FFQ and 24hR). For energy, de-attenuated $r$ was 0.55 and the values for macronutrients ranged from 0.21 for total fat to 0.42 for carbohydrate. De-attenuated correlations for micronutrients ranged from 0.33 for Fe to 0.65 for $\mathrm{Ca}$. When evaluating FFQ1 and FFQ2 separately, it was observed that the average from the FFQ showed higher correlations for most nutrients as compared with the average from the three $24 \mathrm{hR}$ (data not shown).

By analysing the percentage of exact agreement between quartiles of energy and nutrient intakes as measured by the FFQ and $24 \mathrm{hR}$, it was possible to observe values between $52.7 \%$ and $27.4 \%$ for $\mathrm{Ca}$ and total fat, respectively. The average percentage of disagreement between the methods was $4.1 \%$, ranging from $0 \%$ for $\mathrm{Ca}$ to $7.4 \%$ for fat. The $\kappa_{\mathrm{w}}$ values ranged from 0.25 for total fat to 0.62 for $\mathrm{Ca}$. For the nutrients evaluated, $46 \%$ had a $\kappa_{\mathrm{w}}$ value greater than $0 \cdot 40$ (Table 3 ).

Table 4 shows the mean differences between the methods with the respective upper and lower $95 \%$ LOA. The mean energy difference was $2696 \cdot 13 \mathrm{~kJ}$ (upper/lower LOA= $8173.40 \mathrm{~kJ}, 2781.15 \mathrm{~kJ})$. For carbohydrate the observed difference was approximately $100 \mathrm{~g}$ (upper/lower LOA= $295.88 \mathrm{~g},-94.12 \mathrm{~g}$ ). Protein and total fat showed a similar mean intake differences between the methods: $29 \cdot 17 \mathrm{~g}$ (upper/lower LOA $=35.29 \mathrm{~g}, 23.05 \mathrm{~g}$ ) for protein and the same $29 \cdot 17 \mathrm{~g}$ (upper/lower LOA $=88.91 \mathrm{~g},-30.57 \mathrm{~g}$ ) for total fat.

Figure 3 provides scatter plots (Bland-Atman) of the differences in intake between the two methods (FFQ and $24 \mathrm{hR}) v$. the mean intakes of the two methods for energy 
(a)

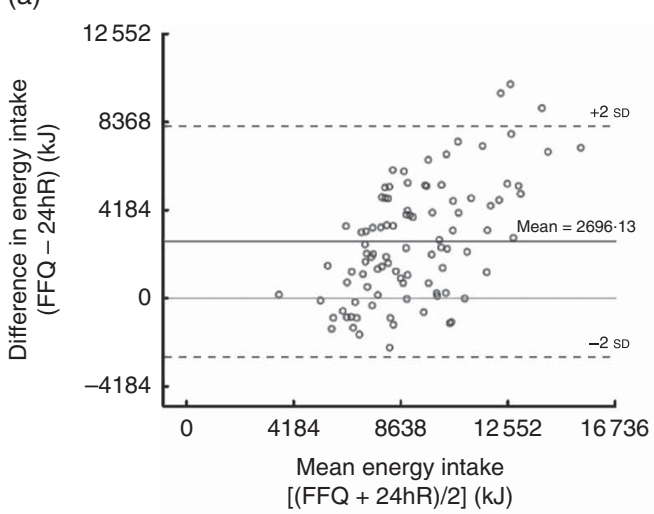

(c)

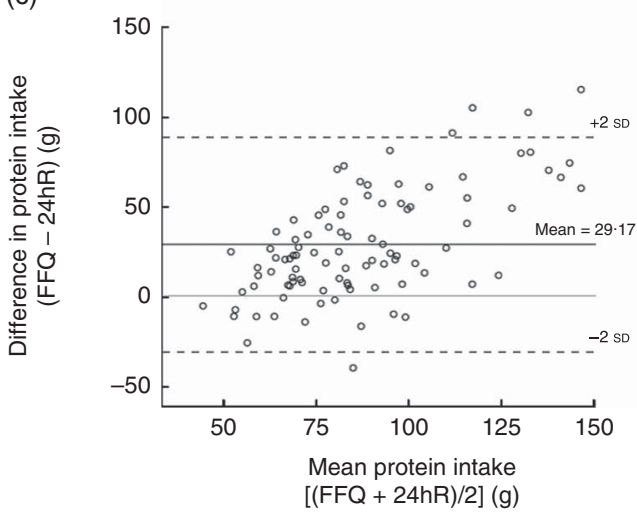

(b)

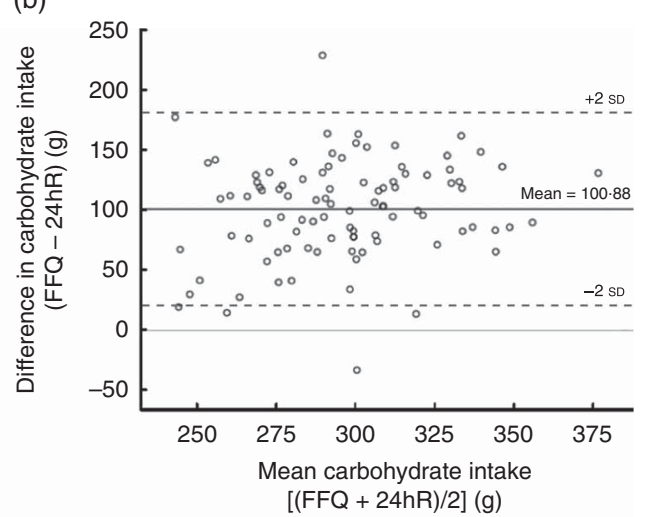

(d)

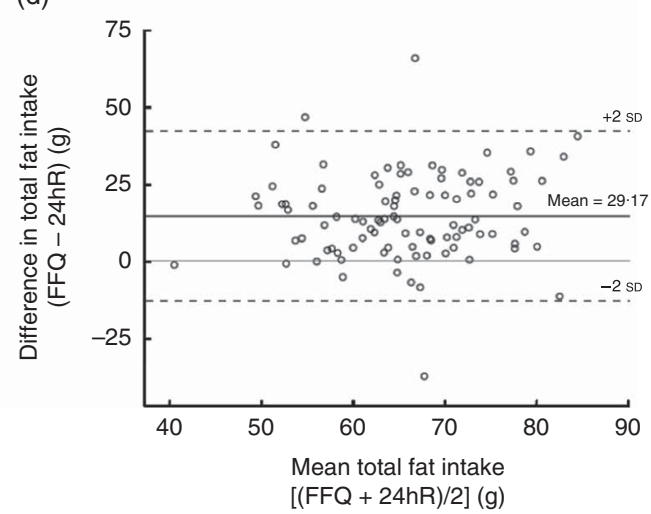

Fig. 3 Bland-Altman plots assessing the relative validity of the newly developed FFQ (FFQ-Quito) among ninety-five adults, Quito, Ecuador, November 2011-August 2012. The difference in intake between the average of the two FFQ and the average of the three $24 \mathrm{~h}$ recalls $(24 \mathrm{hR})$ is plotted $v$. the mean intake from the two methods for: (a) energy, (b) carbohydrate, (c) protein and (d) total fat. _ represents the mean difference (bias) and - - - - - represent the limits of agreement

and macronutrients. Comparisons of energy and protein demonstrated greater variability, with a tendency for bias to increase according to the increase in average energy intake measured by $24 \mathrm{hR}$ and energy intake measured by FFQ. This indicates that higher energy and protein intake enhanced disagreement between the methods. With respect to carbohydrate, there was a mean difference of $100.88 \mathrm{~g}$ between methods, which was constant for all levels of intake. In contrast, the scatter plot for total fat showed a continuous bias, although it was smaller and similar for all levels of intake.

\section{Discussion}

The present study developed an FFQ for the adult population of Quito, Ecuador, and evaluated its reliability and relative validity. The results show that the tool provides reliable measurements and satisfactory relative validity for most macro- and micronutrients.

It is worth noting that the present study is the first one that proposes a validated FFQ for Ecuador. The findings are based on a rigorous study design with regard to selection of participants, sample size, instrument design, validation and statistical analyses. Standardization of data collection included training and certification of interviewers and the use of food photograph albums to carry out the $24 \mathrm{hR}$ and FFQ. Collection of $24 \mathrm{hR}$ data included consumption on Sundays because food intake on that day is often significantly higher than on the other days of the week ${ }^{(30)}$. Some limitations should also be noted. Both FFQ and $24 \mathrm{hR}$ rely on the ability of respondents to accurately recall the past, so that some degree of measurement errors due to under- or overreporting of consumption is inevitable. Nevertheless, the process of data collection was designed to optimize the participation in order to reduce measurement errors and follow-up losses.

With regard to reliability, we used relative comparison techniques such as the ICC, which allows evaluation of the exact agreement between the variables analysed without presuming a linear relationship as in the Pearson correlation coefficient ${ }^{(34)}$. In the present study, the adjusted, uncorrected correlation coefficients for energy and nutrients were always greater than 0.77 and although the adjustment for energy reduced the correlations, the adjusted and de-attenuated values were within acceptable range, with the lowest value of 0.62 for protein and the highest value of 0.88 for $\mathrm{Ca}$. Similar ICC were reported by other reliability studies ${ }^{(34,35)}$. 
Concerning the validation study, it was observed that for most of the nutrients considered, the within-subject variance was greater than the variance between subjects. There was a predominance of females in the study and it has been reported that generally females have higher ratios of withinto between-subject variance than males ${ }^{(30,36,37)}$. The average intake values for energy and macro- and micronutrients were higher in the FFQ compared with the intake averages established in the $24 \mathrm{hR}$. This finding is consistent with those of other studies, which show overestimation in FFQ when compared with other methods such as recalls and food records ${ }^{(12,16,18,34,35,38-40)}$. The study also found that the adjustment for energy reduced the correlation values for total fat, carbohydrate, protein, cholesterol and to a lesser degree $\mathrm{Na}$; these results are also similar to those of other studies ${ }^{(16,18,38,40-43)}$. According to Willett ${ }^{(9)}$, the adjustment for total energy increases the correlation coefficient when variability in nutrient intake is related to energy intake, but produces a decrease when the nutrient variability is due to systematic errors in under- or overreporting of food intake. Given the results of our study, we cannot rule out that these errors are present in the reports of both methods. Over the years, researchers have recognized that intake values measured by FFQ are subject to both systematic and random errors ${ }^{(44)}$.

Analysis of the Bland-Altman plots demonstrates the degree to which the FFQ is inconsistent with the reference method, thus demonstrating a constant bias with a tendency to increase according to the level of intake. The $95 \%$ LOA were very high for $\mathrm{Na}$ (upper/lower $\mathrm{LOA}=1554.29 \mathrm{mg},-1231.45 \mathrm{mg}$ ) and vitamin A (upper/ lower $\mathrm{LOA}=1423.88 \mu \mathrm{g},-229.34 \mu \mathrm{g}$ ). This finding is also consistent with those of other studies ${ }^{(12,45)}$, indicating that wide LOA between FFQ and $24 \mathrm{hR}$ are common. This conclusion highlights the difficulties in using the FFQ to estimate absolute intakes of some nutrients.

With regard to further use of the tool discussed here, the FFQ-Quito accurately determines nutrients considered as protective or risk markers for chronic non-communicable diseases. In the context of the epidemiological and nutrition transitions, this point is increasingly important because taking new patterns of food consumption into consideration allows for more informed development of strategies and nutritional recommendations aimed at improving the health status of the population. The FFQ-Quito showed reasonable agreement for fibre $(r=0.53)$, Ca $(r=0.65)$, vitamin C $(r=0.62)$ and $\mathrm{K}(r=0.62)$; these markers are considered protective for metabolic syndrome, diabetes, CVD and cancer $^{(46)}$. Likewise, for non-communicable disease risk markers, we also found a reasonable agreement between the methods for nutrients such as saturated fat $(r=0 \cdot 48)$ and cholesterol $(r=0.45)$. In nutritional epidemiology, one of the main requirements when using the FFQ to estimate dietary intake is to analyse the diet-disease relationship. Accordingly, more important than correctly estimating food intake is the ability to correctly classify individuals according to intake levels ${ }^{(9)}$. The results of the present study indicate that the FFQ-Quito fills a real need since it has a low average percentage ( $4.1 \%)$ of disagreement between intake quartiles according to the different methods.

\section{Conclusion}

In conclusion, our results suggest that the FFQ developed for Quito, Ecuador, can be used to assess usual nutrient intake since it provides reliable measures for classifying individuals by their nutrient intakes and has reasonable relative validity, especially for protective and risk markers of chronic non-communicable diseases. To our knowledge, this is the first FFQ designed to assess food and nutrient intakes in Quito and will be a useful tool in future research, particularly in studies on the relationship between diet and chronic diseases. This tool also provides a valuable contribution for policy makers since it may be useful in evaluating interventions or policies aimed at promoting healthy eating in this population.

\section{Acknowledgements}

Acknowledgements: The authors are grateful to the participants of the study. They also thank the Nutrition Department/Public Health School from the Universidad San Francisco de Quito for its support. Financial support: This study was supported by the Brazilian National Council for Research and Development (CNPq; grant number 190638/2010-9). CNPq had no role in the design, analysis or writing of this article. Conflict of interest: None. Authorship: K.M.S.-J., M.B.N. and M.D. contributed to concept development, conducted the analysis and interpreted the data. K.M.S.-J. was responsible for execution of the study and processing the data, and drafted the manuscript. All authors critically reviewed the manuscript and have responsibility for the final content. Ethics of buman subject participation: This research project was approved by the Ethics Committees at the Universidad San Francisco de Quito (Ecuador) and at the Universidade Federal do Rio Grande do Sul (Brazil).

\section{Supplementary material}

To view supplementary material for this article, please visit http://dx.doi.org/10.1017/S1368980014003346

\section{References}

1. Alwan A, Amstrong T, Cowan M et al. (2011) France. In Noncommunicable Diseases Country Profiles 2011, p.76. Geneva: WHO; available at http://www.who.int/nmh/ publications/ncd_profiles2011/en/

2. Alwan A, Maclean DR, Riley LM et al. (2010) Monitoring and surveillance of chronic non-communicable diseases: 
progress and capacity in high-burden countries. Lancet 376, 1861-1868.

3. Freire WB, Ramírez-Luzuriaga MJ, Belmont P et al. (2014) Tomo I: Encuesta Nacional de Salud y Nutrición ENSANUTECU 2012 (Volume I: Ecuadorian National Health and Nutrition Survey ENSANUT-ECU 2012). Quito: Ministerio de Salud Pública/Instituto Nacional de Estadística y Censos.

4. Beaglehole R, Bonita R, Horton R et al. (2011) Priority actions for the non-communicable disease crisis. Lancet 377, 1438-1447.

5. Millen BE \& Quatromoni PA (2001) Nutritional research within the Framingham Heart Study. J Nutr Health Aging $\mathbf{5}$, 139-143.

6. Nelson NJ (2000) Nurses' Health Study: nurses helping science and themselves. J Natl Cancer Inst 92, 597-599.

7. Nusser S, Carriquirry A, Dodd K et al. (1996) A semiparametric transformation approach to estimating usual daily intake distributions. J Am Stat Assoc 91, 1440-1449.

8. Gibson RS (2005) Principles of Nutritional Assessment, 2nd ed. New York: Oxford University Press, Inc.

9. Willett W (editor) (1998) Nutritional Epidemiology, 2nd ed. New York: Oxford University Press, Inc.

10. Thompson FE \& Subar AF (2013) Dietary assessment methodology. In Nutrition in the Prevention and Treatment of Disease, pp. 5-46 [AM Coulston, CJ Boushey and MG Ferruzzi, editors]. Waltham, MA: Elsevier Inc.

11. Prentice RL (2010) Dietary assessment and the reliability of nutritional epidemiology research reports. J Natl Cancer Inst 102, 583-585.

12. Dehghan M, Martinez S, Zhang X et al. (2012) Relative validity of an FFQ to estimate daily food and nutrient intakes for Chilean adults. Public Health Nutr 16, 1782-1788.

13. Cade J, Thompson R, Burley V et al. (2002) Development, validation and utilisation of food-frequency questionnaires a review. Public Health Nutr 5, 567-587.

14. Chinnock A (2011) Development of a food frequency questionnaire and a comparison with food records. Perspect Nutr Hum 13, 57-69.

15. Dehghan M, López Jaramillo P, Dueñas R et al. (2012) Development and validation of a quantitative food frequency questionnaire among rural- and urban-dwelling adults in Colombia. J Nutr Educ Behav 44, 609-613.

16. Hernández-Aila M, Romiu I, Parra S et al. (1998) Validity and reproducibility of a food frequency questionnaire to assess dietary intake of women living in Mexico City. Salud Publica Mex 40, 133-140.

17. Henn RL, Fuchs SC, Moreira LB et al. (2010) Development and validation of a food frequency questionnaire (FFQ-Porto Alegre) for adolescent, adult and elderly populations from Southern Brazil. Cad Saude Publica 26, 2068-2079.

18. Dehghan M, del Cerro S, Zhang X et al. (2012) Validation of a semi-quantitative food frequency questionnaire for Argentinean adults. PLoS One 7, e37958.

19. Ministerio de Inclusión Económica y Social (2010) Atlas Fotográfico de Porciones de Alimentos - Instrumento de Apoyo a las Encuestas de Consumo. Quito: MIES, Aliméntate Ecuador.

20. Zaboto C, Viviana R \& Gil M (1996) Registro Fotográfico para Inquéritos Dietéticos: Utensílios e Porções. Goiânia: Universidade Federal de Goiás.

21. Block G, Dresser CM, Hartman AM et al. (1985) Nutrient sources in the American diet: quantitative data from the NHANES II survey. I. Vitamins and minerals. Am J Epidemiol 122, $13-26$.

22. Sichieri R \& Everhart JE (1998) Validity of a Brazilian food frequency questionnaire against dietary recalls and estimated energy intake. Nutr Res 18, 1649-1659.

23. Burley VJ, Cade JE, Margetts B et al. (2000) Consensus document on the development, validation and utilization of food frequency questionnaires. Presented at Fourth International Conference on Dietary Assessment Methods, Tuscon, AZ, USA, 17-20 September 2000.

24. Moshfegh AJ, Rhodes DG, Baer DJ et al. (2008) The US Department of Agriculture Automated Multiple-Pass Method reduces bias in the collection of energy intakes. Am J Clin Nutr 88, 324-332.

25. Ramírez-Luzuriaga MJ, Silva-Jaramillo KM, Belmont $\mathrm{P}$ et al. (2014) Tabla de composición de alimentos para Ecuador: Compilación del Equipo técnico de la ENSANUT-ECU (Ecuadorian Food Composition Database: Technical Compilation). Quito: Ministerio de Salud Pública del Ecuador.

26. US Department of Agriculture, Agricultural Research Service (2012) National Nutrient Database for Standard Reference, Release 25. http://www.ars.usda.gov/ba/bhnrc/ ndl (accessed January 2012).

27. Universidade Federal de Pelotas (2009) ADSNutri - Ferramenta para Análise de Dietas. http://www.heufpel.com.br/ inicio.php?area=sistemas (accessed September 2011).

28. Camey S, Nunes L \& Cruz L (2010) Beanplot a new graphical tool. Rev HCPA 2, 185-191.

29. Willett WC, Howe GR \& Kushi LH (1997) Adjustment for total energy intake in epidemiologic studies. Am J Clin Nutr 65, 4 Suppl., 1220S-1228S.

30. Beaton GH, Milner J, McGuire V et al. (1983) Source of variance in 24-hour dietary recall data: implications for nutrition study design and interpretation. Carbohydrate sources, vitamins, and minerals. Am J Clin Nutr 37, 986-995.

31. Liu K, Stamler J, Dyer A et al. (1978) Statistical methods to assess and minimize the role of intra-individual variability in obscuring the relationship between dietary lipids and serum cholesterol. J Chronic Dis 31, 399-418.

32. Bland J \& Altman D (1986) Statistical methods for assessing agreement between two methods of clinical measurements. Lancet 1, 307-310.

33. Bland JM \& Altman DG (1995) Comparing methods of measurement: why plotting difference against standard method is misleading. Lancet 346, 1085-1087.

34. Molina MDCB Benseñor IM, Cardoso L de O et al. (2013) Reproducibility and relative validity of the food frequency questionnaire used in the ELSA-Brasil. Cad Saude Publica 29, 379-389.

35. Jackson MD, Motswagole BS, Kwape LD et al. (2013) Validation and reproducibility of an FFQ for use among adults in Botswana. Public Health Nutr 16, 1995-2004.

36. Nelson M, Black AE, Morris JA et al. (1989) Between- and within-subject variation in nutrient intake from infancy to old age: estimating the number of days required to rank dietary intakes with desired precision. Am J Clin Nutr 50, 155-167.

37. Lora KR, Lewis NM, Eskridge KM et al. (2010) Validity and reliability of an omega-3 fatty acid food frequency questionnaire for first-generation Midwestern Latinas. Nutr Res 30, 550-557.

38. Zanolla AF, Olinto MTA, Henn RL et al. (2009) Assessment of reproducibility and validity of a food frequency questionnaire in a sample of adults living in Porto Alegre, Rio Grande do Sul State, Brazil. Cad Saude Publica 25, 840-848.

39. Kroke A, Klipstein-Grobusch K, Voss S, Möseneder J et al. (1999) Validation of a self-administered food-frequency questionnaire administered in the European Prospective Investigation into Cancer and Nutrition (EPIC) Study: comparison of energy, protein, and macronutrient intakes estimated with the doubly labeled water, urinary nitrogen, and repeated 24-h dietary recall methods. Am J Clin Nutr $\mathbf{7 0}$, 439-447. 
40. Block G, Wakimoto P, Jensen C et al. (2006) Validation of a food frequency questionnaire for Hispanics. Prev Chronic Dis 3, A77.

41. Ocké MC, Bueno-de-Mesquita HB, Pols MA et al. (1997) The Dutch EPIC food frequency questionnaire. II. Relative validity and reproducibility for nutrients. Int J Epidemiol 26, Suppl. 1, 49S-58S.

42. Bohlscheid-Thomas S, Hoting I, Boeing H et al. (1997) Reproducibility and relative validity of energy and macronutrient intake of a food frequency questionnaire developed for the German part of the EPIC project. European Prospective Investigation into Cancer and Nutrition. Int J Epidemiol 26, Suppl. 1, S71-S81.
43. Barrat E, Aubineau N, Maillot M et al. (2012) Repeatability and relative validity of a quantitative food-frequency questionnaire among French adults. Food Nutr Res 2012, 56.

44. Liu K (1994) Statistical issues related to semiquantitative food-frequency questionnaires. Am J Clin Nutr 59, 1 Suppl., 262S-265S.

45. Sam CH, Skeaff S \& Skidmore PM (2014) A comprehensive FFQ developed for use in New Zealand adults: reliability and validity for nutrient intakes. Public Health Nutr 17, 287-296.

46. Aune D, Lau R, Chan DSM et al. (2012) Dairy products and colorectal cancer risk: a systematic review and metaanalysis of cohort studies. Ann Oncol 23, 37-45. 